\title{
Dynamic left ventricular outflow tract obstruction secondary to hypovolemia in a German Shepard dog with splenic hemangiosarcoma
}

\author{
Takuma AOKI ${ }^{1) *}$, Hiroshi SUNAHARA ${ }^{1)}$, Keisuke SUGIMOTO ${ }^{1)}$, Tetsuro ITO $^{2)}$, Eiichi KANAI ${ }^{3)}$, Sakurako NEO ${ }^{4}$, \\ Yoko FUJII ${ }^{1)}$ and Yoshito WAKAO ${ }^{1)}$ \\ ${ }^{1)}$ Laboratory of Veterinary Surgery I, School of Veterinary Medicine, Azabu University, 1-17-71 Fuchinobe, Chuo-ku, Sagamihara-shi, \\ Kanagawa 252-5201, Japan \\ ${ }^{2)}$ Laboratory of Small Animal Clinics, School of Veterinary Medicine, Azabu University, 1-17-71 Fuchinobe, Chuo-ku, Sagamihara-shi, \\ Kanagawa 252-5201, Japan \\ ${ }^{3)}$ Laboratory of Veterinary Radiology, School of Veterinary Medicine, Azabu University, 1-17-71 Fuchinobe, Chuo-ku, Sagamihara-shi, \\ Kanagawa 252-5201, Japan \\ 4) Laboratory of Veterinary Internal Medicine II, School of Veterinary Medicine, Azabu University, 1-17-71 Fuchinobe, Chuo-ku, \\ Sagamihara-shi, Kanagawa 252-5201, Japan
}

(Received 30 September 2014/Accepted 17 April 2015/Published online in J-STAGE 28 April 2015)

ABSTRACT. Dynamic left ventricular outflow tract obstruction (DLVOTO) is a common condition in cats and humans. In this case report, a dog is described with DLVOTO secondary to severe intra-abdominal hemorrhage caused by a hemangiosarcoma. The dog was a 9-year-old, $35.7-\mathrm{kg}$, spayed female German Shepard dog that presented with a history of tachypnea and collapse. A Levine II/VI systolic murmur was present at the heart base. Abdominal ultrasonography revealed a splenic mass and a large amount of ascites. Echocardiography showed a reduced left ventricular diameter and an increased aortic velocity caused by systolic anterior motion (SAM) of the mitral valve apparatus. The heart murmur and the SAM were resolved after treatment including a splenectomy and a blood transfusion.

KEY WORDS: canine, dynamic left ventricular outflow tract obstruction, hemangiosarcoma, hypovolemia, systolic anterior motion

doi: 10.1292/jvms.14-0508; J. Vet. Med. Sci. 77(9): 1187-1190, 2015

Dynamic left ventricular outflow tract obstruction (DLVOTO) is a common condition in cats and humans and can be seen with or without hypertrophic cardiomyopathy (HCM) [7, 8]. Reports of dogs with HCM have been published [14, 17, 18]; however, other causes of DLVOTO have also been reported $[4,13]$. Hypertrophy of the left ventricle, secondary to DLVOTO following systolic anterior motion (SAM) of the mitral valve apparatus is observed, especially in young terrier-breed dogs. This is similar to what is seen in cats with HCM; however, the DLVOTO in these young dogs is resolved after maturation or after treatment with betablockers $[4,13]$. Other causes of DLVOTO are a reduced left ventricular volume, a decreased afterload or an increased contractility in cats and in humans $[7,19]$. Indeed, DLVOTO secondary to furosemide usage was observed in a dog with pulmonary hypertension, which may have been due to the concurrent occurrences of reduced pulmonary venous drainage secondary to the pulmonary hypertension and reduced body fluid volume following the use of diuretics [16]. In this report, we encountered a dog with transient DLVOTO following hypovolemia caused by severe intra-abdominal

*Correspondence to: Aoki, T., Laboratory of Veterinary Surgery I, School of Veterinary Medicine, Azabu University, 1-17-71 Fuchinobe, Chuo-ku, Sagamihara-shi, Kanagawa 252-5201, Japan.e-mail: t-aoki@azabu-u.ac.jp

(C2015 The Japanese Society of Veterinary Science

This is an open-access article distributed under the terms of the Creative Commons Attribution Non-Commercial No Derivatives (by-nc-nd) License $<$ http://creativecommons.org/licenses/by-nc-nd/3.0/>. hemorrhage secondary to a splenic hemangiosarcoma. To our knowledge, secondary DLVOTO following severe hemorrhage in dogs has not been described in previous reports.

A 9-year-old spayed female German Shepherd Dog, weighing $35.7 \mathrm{~kg}$, was presented to the referring veterinarian with signs of tachypnea, collapse and increased abdominal girth after walking. Hypodermoclysis was performed before referral to the veterinary hospital of Azabu University for an emergency laparotomy, because severe intra-abdominal hemorrhage was suspected after the referring veterinarian performed abdominal fluid analysis.

On physical examination, the body temperature was $37.7^{\circ} \mathrm{C}$, the heart rate was $174 \mathrm{bpm}$, and the respiration rate was increased (42/min) and labored. Femoral pulses were detectable, and capillary refill time was within $1 \mathrm{sec}$. The systolic blood pressure was measured using a Doppler ultrasound device and was $110 \mathrm{mmHg}$. Auscultation revealed a systolic murmur with the punctum maximum over the left heart base (Levine II/VI), which had not been detected previously. Abdominal ultrasonography revealed a splenic mass with an $8-\mathrm{cm}$ diameter and a large amount of ascites. The ascites properties were not examined at our hospital, because the referring veterinarian had highly suspected hemorrhage from splenic rupture after performing abdominal fluid analysis. Hematology results revealed a red cell count of $599.0 \times 10^{4}$ cells $/ \mu l$ (reference range: $550.0-850.0 \times 10^{4}$ cells $/ \mu l$ ); a packed cell volume (PCV) of $41.3 \%$ (reference range: $37.0-55.0 \%$ ); a hemoglobin concentration of 13.8 $\mathrm{g} / \mathrm{d} l$ (reference range: $12.0-18.0 \mathrm{~g} / \mathrm{d} l$ ); a mean corpuscular volume of $68.9 \mathrm{fl}$ (reference range: 66-77 fl); and a mean 
A
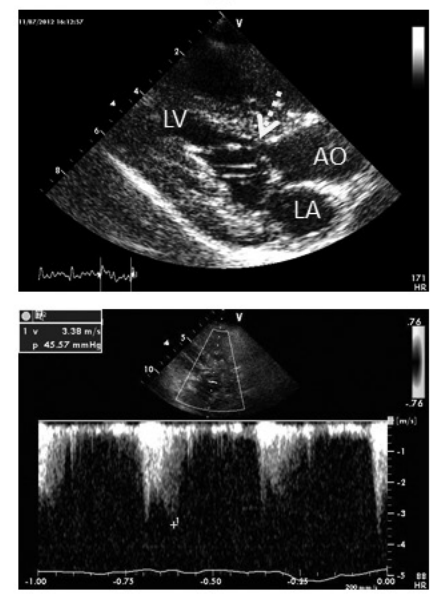

B

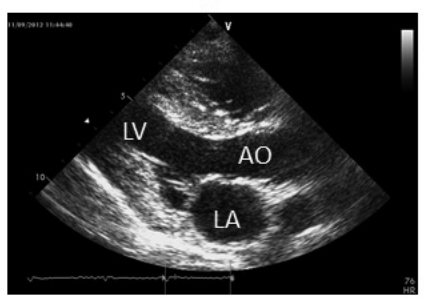

C
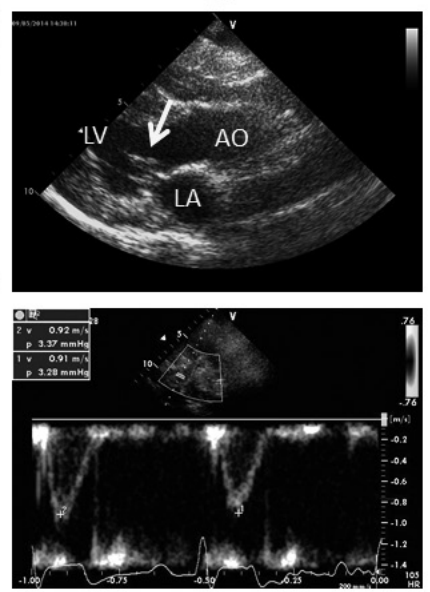

Fig. 1. Echocardiogram A) At the first presentation (Day 0): Systolic anterior motion of the mitral valve apparatus was observed on the right parasternal left ventricular long axis view (dotted arrow, top). The aortic flow was increased $(3.38 \mathrm{~m} / \mathrm{sec})$ with a scimitar shape; however, the image quality was not sufficient, because echocardiography was performed emergently (bottom). B) Day 9: SAM of the mitral valve apparatus has resolved (top). C) Day 667: Septal leaflet and/or chordae tendineae appear close to the left ventricular outflow tract in systole (arrow, top). The aortic flow was $0.92 \mathrm{~m} / \mathrm{sec}$ with a normal profile (bottom).

corpuscular hemoglobin concentration of $33.4 \mathrm{~g} / \mathrm{d} l$ (reference range: $32.0-36.0 \mathrm{~g} / \mathrm{d} l$ ). In addition to these normal values, leukogram was consistent with a mature neutrophilia (segmented neutrophil of 27,342 cells/ $\mu l$, reference range: $3,000-11,500$ cells $/ \mu l$; lymphocyte of 743 cells/d $l$, reference range: $1,000-4,800$ cells $/ \mathrm{d} l$; and monocyte of 1,635 cells $/ \mu l$, reference range: $150-1,350$ cells $/ \mu l$ ). Biochemical examination revealed a mild azotemia (blood urea nitrogen: $33.4 \mathrm{mg}$ / $\mathrm{d} l$, reference range: $9.2-29.9 \mathrm{mg} / \mathrm{d} l$ ) and a mild hypoproteinemia (total protein: $5.0 \mathrm{~g} / \mathrm{d} l$, reference range: $5.1-7.7 \mathrm{~g} / \mathrm{d} l$ ). Blood coagulation tests involving fibrin degradation products did not show any significant abnormalities apart from an elevation of C-reactive protein $(2.95 \mathrm{mg} / \mathrm{d} l$, reference range: $<1.0 \mathrm{mg} / \mathrm{d} l$ ). Thoracic radiography revealed a reduced heart size (vertebral heart score 9.1 vertebrae [v], reference range: $9.7 \pm 0.5 \mathrm{v}$ [2]) and a narrowed caudal vena cava. Echocardiography showed a reduced normalized left ventricular end-diastolic diameter (LVDd-index) at 0.86, reference range: 1.27-1.85 [5]; a reduced normalized end-systolic left ventricular diameter (LVDs-index) at 0.55 , reference range: $0.71-1.26$ [5]; and an increased end-diastolic left ventricular free wall thickness [LVFd] at $1.38 \mathrm{~cm}$, reference range: $0.66-1.36 \mathrm{~cm}$ [5]. The LA/Ao ratio was 1.27 . The aortic velocity was $3.38 \mathrm{~m} / \mathrm{sec}$ with a scimitar-shaped profile caused by the systolic anterior motion (SAM) of the mitral valve apparatus; however, because this examination was performed emergently, the image quality was not sufficient (Fig. 1A). Color-flow Doppler echocardiography revealed a slight mitral regurgitation secondary to SAM of the mitral valve apparatus. The bodyweight, measured 9 days after the first presentation when the dog was recovered to her normal clinical status, was $33.6 \mathrm{~kg}$. This bodyweight was used for normalization of the echocardiographic parameters, because the bodyweight at first presentation could have been affected by the severe hemorrhage and the treatment. Splenic rupture was suspected after the initial examinations, and emergency laparotomy was performed in combination with a transfusion of whole blood $(400 \mathrm{ml})$ and infusion of hydroxyethylated starch $(150 \mathrm{ml})$. The general anesthesia protocol consisted of induction with fentanyl (10 $\mu \mathrm{g} / \mathrm{kg}$, intravenously [IV]), midazolam (0.2 mg/kg, IV) and propofol (1-2 mg/kg, IV); and maintenance with fentanyl $(5 \mu \mathrm{g} / \mathrm{kg} / \mathrm{hr}$, constant rate infusion [CRI]) and isoflurane (1.5-2.0\% in $100 \%$ oxygen). Cefazolin was administered before surgery $(25 \mathrm{mg} / \mathrm{kg}, \mathrm{IV})$ and continued for 7 days post surgery $(25 \mathrm{mg} / \mathrm{kg}$, per os, q $8 \mathrm{hr}$ ). Lactated Ringer's solution was administered during surgery $(10 \mathrm{~m} / / \mathrm{kg} / \mathrm{hr}, \mathrm{IV})$ and was continued for 1 day after surgery $(2-5 \mathrm{ml} / \mathrm{kg} / \mathrm{hr}, \mathrm{IV})$. Laparotomy was performed via midline incision. Rupture of spleen was evident, and a large amount of hemorrhagic ascites $(900 \mathrm{ml})$ was observed in the abdominal cavity. Although ventricular bigeminy was observed during surgery, this resolved after the administration of lidocaine ( $2 \mathrm{mg} / \mathrm{kg}$, IV bolus, followed by $25-80 \mathrm{mcg}$ / $\mathrm{kg} / \mathrm{min}, \mathrm{CRI})$. A splenectomy was performed routinely using absorbable monofilament sutures. The abdominal musculature, subcutaneous tissue and skin were closed routinely, and the dog recovered uneventfully from general anesthesia. The fentanyl was continued via the transdermal route for postoperative analgesia. The pathological examination of the ruptured spleen revealed the presence of a splenic hemangiosarcoma. The day after surgery, no heart murmur could be detected. However, the blood results revealed mild anemia with a red cell count of $486.0 \times 10^{4} / \mu \mathrm{l}$, a packed cell volume of $33.3 \%$ and a hemoglobin concentration of $11.1 \mathrm{~g} / \mathrm{d} l$. The owner declined the advised adjunctive chemotherapy. The dog was discharged at day 9 , after resolution of the clinical 
signs including the heart murmur. The echocardiography was performed at the day of discharge and revealed that the LVDd-index and LVWd were within normal range with a LVDd-index of 1.75 , and a LVWd of $1.24 \mathrm{~cm}$. The LVDsindex was 1.49 , and the fractional shortening was $49.5 \%$. The LA/Ao ratio was 1.56. SAM of the mitral valve apparatus was not detected, although data of the aortic flow were lacking (Fig. 1B). The dog was presented again 667 days after the first presentation with two 3 to $4 \mathrm{~cm}$ cutaneous tumors, one on the left exterior cubital region and one on the right interior tarsus. No systemic signs were present, and both tumors were pathologically diagnosed as a hemangioma. No evidence of recurrence or metastasis of the splenic hemangiosarcoma was detected during diagnostic imaging including abdominal ultrasonography, echocardiography, and thoracic and abdominal radiography. On physical examination, no heart murmur was detected. The VHS was within the normal range on thoracic radiography at $9.4 \mathrm{v}$. The echocardiography revealed an end-diastolic left ventricular diameter that was smaller than measured at day 9 but within the normal range. The LVDd-indices were 1.41 and 1.75 at day 667 and day 9, respectively. The LVWd and LVDs-indices were also within the normal range at 1.09 and 0.90 , respectively. The LA/Ao ratio was 1.32 . The DLVOTO secondary to SAM of the mitral valve apparatus had disappeared, and the aortic velocity was $0.92 \mathrm{~m} / \mathrm{s}$ with a normal profile (Fig. 1C); however, the mitral septal leaflet and/or the chordae tendineae appeared close to the LVOT in systole on the right parasternal left ventricular long axis view (Fig. 1C).

DLVOTO secondary to SAM of the mitral valve apparatus is a common manifestation in humans and cats with HCM [8]; however, HCM is an uncommon finding in dogs $[12,14,18]$. Apart from HCM, DLVOTO can also be associated with congenital heart disease. Hypertrophy of the left ventricle resolves gradually when SAM of the mitral valve apparatus disappears during maturation. This congenital type of DLVOTO is commonly detected as a benign temporary systolic heart murmur in young dogs, especially in young terrier-breeds [4, 13]. Beta-blockers were reported to improve the obstruction following DLVOTO markedly in these young dogs $[4,13]$. In the current case report, DLVOTO did not appear to be caused by a congenital problem, because the dog had no record of a heart murmur at a young age. In addition, HCM was not the cause of DLVOTO in this dog, because hypertrophy of the left ventricle was resolved after the transfusion and even at day 667. Indeed, increased wall thickness secondary to severe dehydration has been described in cats, i.e., "pseudohypertrophy" [3]. The following pathologies could also be a cause of DLVOTO: 1) a decreased preload in which a decreased left ventricular diameter could narrow the left ventricular outflow tract (LVOT); 2) an increased contractility of the left ventricle in which hyperkinesia of the left ventricle could narrow the LVOT as described in excited cats [7]; and 3) a decreased afterload in which hyperkinesia of the left ventricle after a decreased peripheral vascular resistance could narrow the LVOT $[15,19]$. In this case, hypovolemia secondary to acute severe abdominal hemorrhage appeared to be the main cause of DLVOTO. Indeed, this situation induces narrowing of the LVOT $[1,11]$. In addition, increased sympathetic activity and endogenous catecholamine release following severe hemorrhage [1] might affect the DLVOTO, because of increased cardiac contractility. However, the contractility of the left ventricle might have been weakened, because of the reduced preload, according to the Frank-Starling law [15].

SAM of the mitral valve apparatus could be caused by an elongated mitral leaflet due to degenerative mitral valve disease or mitral valve dysplasia, excessive mitral annuloplasty, or abnormal placement of the papillary muscle due to mitral valve dysplasia $[6,10]$. In this case, an elongated mitral leaflet or malalignment of the papillary muscles could not be excluded; although, mitral valve regurgitation secondary to degenerative mitral valve disease could not be detected even at day 667. Mitral valve dysplasia is another possible cause of DLVOTO in this dog, since the septal leaflet and/or the chordae tendineae appeared close to the LVOT in systole at day 667 (Fig. 1C, top). Mitral valve dysplasia is reported to be associated with DLVOTO [6], although it is unlikely that this dog had mitral valve dysplasia, because she had no heart murmur or significant echocardiographic abnormalities, including mitral regurgitation, after the treatments. However, a postmortem examination should be performed to elucidate whether mild mitral valve dysplasia was present in this dog.

Secondary DLVOTO should be considered when systolic cardiac murmur is detected in dogs with severe hemorrhage. However, severe anemia can cause heart murmur because of an increased Reynolds number, which is defined by fictitious force and viscous force $[11,20]$, although the anemia could not have intensified the cardiac murmur in the current case because the acute hemorrhage caused the red blood cells and blood plasma to be equally lost from the vessels into the abdominal cavity [9].

In conclusion, DLVOTO should be considered in dogs with hypovolemia caused by pathologies like acute severe hemorrhage, especially when a systolic heart murmur is detected. DLVOTO can induce a hemodynamic deterioration, because of a low cardiac output combined with a decreased preload [11]. To our knowledge, this is the first report of DLVOTO secondary to acute severe hemorrhage in a dog. Nonetheless, other causes of DLVOTO including elongated mitral leaflet and malalignment of papillary muscles secondary to mitral valve dysplasia cannot be excluded in the current case. Further information needs to be obtained during postmortem examination.

\section{REFERENCES}

1. Auer, J., Berent, R., Weber, T., Lamm, G. and Eber, B. 2005. Catecholamine therapy inducing dynamic left ventricular outflow tract obstruction. Int. J. Cardiol. 101: 325-328. [Medline] [CrossRef]

2. Buchanan, J. W. and Bucheler, J. 1995. Vertebral scale system to measure canine heart size in radiographs. J. Am. Vet. Med. Assoc. 206: 194-199. [Medline]

3. Campbell, F. E. and Kittleson, M. D. 2007. The effect of hydration status on the echocardiographic measurements of normal cats. J. Vet. Intern. Med. 21: 1008-1015. [Medline] [CrossRef] 
4. Connolly, D. J. and Boswood, A. 2003. Dynamic obstruction of the left ventricular outflow tract in four young dogs. J. Small Anim. Pract. 44: 319-325. [Medline] [CrossRef]

5. Cornell, C. C., Kittleson, M. D., Della Torre, P., Haggstrom, J., Lombard, C. W., Pedersen, H. D., Vollmar, A. and Wey, A. 2004. Allometric scaling of M-mode cardiac measurements in normal adult dogs. J. Vet. Intern. Med. 18: 311-321. [Medline] [CrossRef]

6. De Majo, M., Britti, D., Masucci, M., Niutta, P. P. and Pantano, V. 2003. Hypertrophic obstructive cardiomyopathy associated to mitral valve dysplasia in the Dalmatian dog: two cases. Vet. Res. Commun. 27: 391-393. [Medline] [CrossRef]

7. Dirven, M. J., Cornelissen, J. M., Barendse, M. A., van Mook, M. C. and Sterenborg, J. A. 2010. Cause of heart murmurs in 57 apparently healthy cats. Tijdschr. Diergeneeskd. 135: 840-847. [Medline]

8. Fox, P. R., Liu, S. K. and Maron, B. J. 1995. Echocardiographic assessment of spontaneously occurring feline hypertrophic cardiomyopathy. An animal model of human disease. Circulation 92: 2645-2651. [Medline] [CrossRef]

9. Kirby, R. 1995. Transfusion therapy in emergency and critical care medicine. Vet. Clin. North Am. Small Anim. Pract. 25: 1365-1386. [Medline] [CrossRef]

10. Levine, R. A., Vlahakes, G. J., Lefebvre, X., Guerrero, J. L., Cape, E. G., Yoganathan, A. P. and Weyman, A. E. 1995. Papillary muscle displacement causes systolic anterior motion of the mitral valve. Experimental validation and insights into the mechanism of subaortic obstruction. Circulation 91: 1189-1195. [Medline] [CrossRef]

11. Levisman, J. A. 1976. Systolic anterior motion of the mitral valve due to hypovolemia and anemia. Chest 70: 687-688. [Medline] [CrossRef]
12. Liu, S. K., Roberts, W. C. and Maron, B. J. 1993. Comparison of morphologic findings in spontaneously occurring hypertrophic cardiomyopathy in humans, cats and dogs. Am. J. Cardiol. 72: 944-951. [Medline] [CrossRef]

13. Loureiro, J., Smith, S., Fonfara, S., Swift, S., James, R. and Dukes-McEwan, J. 2008. Canine dynamic left ventricular outflow tract obstruction: assessment of myocardial function and clinical outcome. J. Small Anim. Pract. 49: 578-586. [Medline]

14. Marks, C. A. 1993. Hypertrophic cardiomyopathy in a dog. $J$. Am. Vet. Med. Assoc. 203: 1020-1022. [Medline]

15. Opie, L. H. and Perltoth, M. G. 2004. Ventricular function. pp. 355-401. In: Heart Physiology from Cell to Circulation, 4th ed (Opie, L. H. ed.), Lippincott Williams \& Wilkins, Philadelphia.

16. Paige, C. F., Abbott, J. A. and Pyle, R. L. 2007. Systolic anterior motion of the mitral valve associated with right ventricular systolic hypertension in 9 dogs. J. Vet. Cardiol. 9: 9-14. [Medline] [CrossRef]

17. Pang, D., Rondenay, Y., Helie, P., Cuvelliez, S. G. and Troncy, E. 2005. Sudden cardiac death associated with occult hypertrophic cardiomyopathy in a dog under anesthesia. Can. Vet. J. 46: 1122-1125. [Medline]

18. Washizu, M., Takemura, N., Machida, N., Nawa, H., Yamamoto, T., Mitake, H. and Washizu, T. 2003. Hypertrophic cardiomyopathy in an aged dog. J. Vet. Med. Sci. 65: 753-756. [Medline] [CrossRef]

19. Wynne, J. and Braunwald, E. 2001. The cardiomyopathies and myocarditides. pp. 1751-1806. In: Heart Disease: A Textbook of Cardiovascular Medicine, 6th ed. (Braunwald, E. ed.), W. B. Saunders, Philadelphia.

20. Yaphé, W., Giovengo, S. and Moise, N. S. 1993. Severe cardiomegaly secondary to anemia in a kitten. J. Am. Vet. Med. Assoc. 202: 961-964. [Medline] 